УДК 331.108

\title{
АНАЛИЗ И ОЦЕНКА ЭКОНОМИЧЕСКОЙ ЭФФЕКТИВНОСТИ УПРАВЛЕНИЯ ЧЕЛОВЕЧЕСКИМИ РЕСУРСАМИ ОРГАНИЗАЦИИ
}

\author{
Н. Ю. Хвисевич 1
}

${ }^{1}$ Магистр экономических наук, аспирант кафредры экономической теории и логистики, учреждения образования «Брестский государственный технический университет», Брест, Беларусь, e-mail: natkhvisevich@gmail.com

\begin{abstract}
Рефрерат
Процесс управления - это деятельность субъектов управления, руководителей, управленческого персонала организации, направленная на достижение целей предприятия путем реализации определенных функций с использованием методов и принципов управления.

Процесс управления имеет сложную структуру и является совокупностью целенаправленных действий управления в согласовании совместной деятельности коллектива для достижения цели организации. Используя теорию измерения уровней управляемости, можно измерять процессы управления количественными показателями; ввести показатели шкалы измерения и количественные оценки основных и дополнительных показателей процессов управления.
\end{abstract}

В данной статье предлагается решение задачи по анализу и оценке экономической эффрективности специальной функции управление человеческими ресурсами.

Ключевые слова: человеческие ресурсы, уровни управляемости, функции управления, теория измерения, вектор сил развития.

\section{ANALYSIS AND EVALUATION OF ECONOMIC EFFICIENCY OF MANAGEMENT OF HUMAN RESOURCES OF THE ORGANIZATION}

\section{Abstract}

The management process is the activity of the subjects of management, managers, management personnel of the organization, aimed at achieving the goals of the enterprise through the implementation of certain functions using the methods and principles of management.

The management process has a complex structure and is a set of purposeful actions of the board in coordinating the joint activities of the team to achieve the goals of the organization. Using the theory of measuring levels of manageability, it is possible to measure the processes of quantitative management; introduce indicators of the measurement scale and quantitative estimates of the main and additional indicators of management processes.

This article proposes a solution to the problem of analyzing and assessing the economic efficiency of the special function of human resource management.

Keywords: human resources, levels of controllability, management functions, measurement theory, vector of development forces.

\section{Введение}

Эффективность управления организацией подразумевает постоянное внимание как к теории управления, так и к практике. При этом основными рассматриваемыми фракторами являются прозрачность процессов управления, экономическая эффективность использования средств производства, ресурсов и труда. На фоне борьбы между экономическими субъектами в сфере удовлетворения потребностей и ожиданий всех заинтересованных сторон на первый план выдвигаются человеческие качества, такие как способность к логическому и творческому мышлению, умение слушать и убеждать людей, эффективно взаимодействовать с ними и создавать условия для эффективного управления организацией. В таких условиях функционирования руководство предприятием должно больше уделять внимания управлению человеческими ресурсами, подготовке персонала и развитию его способностей быстро реагировать на трансформацию рынка и требований клиентов. Соответственно целью данной работы является изучение основных методов анализа и оценки управления человеческими ресурсами организации, а также выявления преобразований в работе профессионального коллектива и необходимость показать потенциальные пути развития организации для достижения её устойчивого успеха. При написании данной работы необходимо решить следующие задачи: определить и изучить стартовые условия работы организации, обосновать использование методов анализа и оценки управления человеческими ресурсами, исследовать основные показатели и обобщить результаты.

Общие положения анализа и оценки экономической эффективности управления человеческими ресурсами организации

Государственная программа «Комплекс мер по стимулированию внедрения в экономику страны передовых методик и современных международных систем управления качеством» [1] ставит своей целью повысить качество выпускаемой продукции, конкурентоспособность организаций и устойчивость экономики за счет внедрения в организациях современных систем управления, передовых техник качества и эффрективного управления. Разработанная на базе программы «Система мер по управлению качеством в промышленном комплексе Брестской области на 2017-2020 годы» [2] пунктом 4.6 предусматривает разработку предложений по мотивации и стимулированию организаций к интенсивному внедрению на этапах жизненного цикла продукции современных информационных технологий учреждениями образования.

Особое место в улучшении процессов управления организацией занимают стандарты качества управления организацией ISO 9004 - 2010; 2018 [3] и разработанные с учетом их требований инновационные технологии эффективного менеджмента (ИТЭМ), обусловливающие основные характеристики управления организацией. Стандарты дают возможность разработать программу устойчивого развития системы управления устойчивым социально-экономическим развитием организацией.

Процесс управления - это деятельность объединенных в определенную систему субъектов управления, линейных и функциональных руководителей, другого управленческого персонала организации, направленная на достижение целей предприятия путем реализации определенных функций с использованием методов и принципов управления. Сами же процессы управления многообразны: от управления коллективом производственной организации до управления отдельным человеком; от управления в долговременной перспективе до управления оперативной деятельностью; от управления исследованиями по созданию новых видов продукции до управления реализацией.

Процесс управления имеет сложную структуру и является совокупностью целенаправленных действий аппарата управления в сфрере согласования совместной деятельности коллектива для того, чтобы достичь цели организации. Каждый из реальных процессов может быть представлен состоящим из стадий, этапов, фаз, которые в свою очередь состоят из процедур и операций. Используя теорию измерения уровней управляемости [4], можно измерять процессы управления количественными показателями; ввести показатели 
Вестник Брестского государственного технического университета. 2021

шкалы измерения и количественные оценки основных и дополнительных показателей процессов управления; рассчитать динамические характеристики и величину усилий, требуемых для корректировки процессов управления. Этапы процессов управления хозяйственной деятельностью организации можно классифицировать с учетом общих функций управления, к которым относятся этапы:

- процесса принятия решений;

- процесса контроля;

- процесса учета;

- процесса анализа и оценки;

- процесса планирования;

- процесса корректировки;

- процесса стимулирования.

Также этапы процессов управления можно систематизировать по следующим специальным функциям управления:

- политикой;

- маркетингом;

- реализацией;

- закупками;

- финансами;

- системой менеджмента качества;

- у управления человеческими ресурсами;

- управления производством.

В системах управления производственной организации каждый процесс управления имеет «Паспорт процесса управления» и «Карту процедур процесса управления».

Если принять, что управление - это движение в заданном направлении, соответственно и процессы управления также двигаются в заданном направлении. В «Паспорте процесса» обязаны определяться должности владельца, ответственного исполнителя, исполнителей процесса, наименование показателей процесса, единицы изме рения, значения показателей, периодичность измерения, ответственное лицо за измерение, место регистрации и другие адресные данные.

В «Карте процедур процесса» назначается порядок разработки, внедрения и управления документами системы менеджмента качества. Карта процедур определяет, как входные данные: алгоритм процедуры, описание этапов процедуры, ответственного участника, так и выходные данные. В качестве входных данных используются: решение о разработке документов системы менеджмента качества (СМК); график разработки документов СМК; проекты документов СМК; проекты, требующие доработки; согласованные проекты; утвержденные документы СМК; копии документов на местах (актуализированные); информация о необходимости изменений; внесение изменений; решение об отмене документа.

Кроме оценочных показателей достижения цели процесса в характеристику процесса попадают: входные данные процесса (постановщик процесса); мониторинг входных данных процесса (кто, с какой периодичностью, по какой методике, где регистрирует); выходные данные процесса (потребитель данных); мониторинг выходных данных процесса (кто, с какой периодичностью, по какой методике, где регистрирует); менеджмент ресурсов; менеджмент документов; критическая точка процесса; мониторинг в критических точках процесса (кто, с какой периодичностью, по какой методике, кто регистрирует); показатели результативности процесса; совершенствование процесса по результатам анализа со стороны владельца процесса; взаимодействие с другими процессами; реализация процесса. Bсе 14 характеристик процесса описывают каждый шаг движения процесса в заданном направлении с заданной скоростью движения по траектории развития процесса управления. Совокупность двух документов системы менеджмента качества «Паспорт процесса управления» и «Карта процедур процесса управления» определяют характеристики и функции движения системы управления в заданном направлении.

Специальные функции управления, характеризуемые общими, базовыми и временными функциями управления и их параметрами, определяют процессы управления организацией в целом.

Методы измерения и анализа уровней управляемости специальных функций можно разделить на две группы. К первой группе относятся методы, связанные с подготовкой и проведением диагностики специальных функций управления. Вторая группа - методы, связанные с разработкой и предоставлением результатов диагностики на все уровни управления. Специальные функции управления, характеризуемые базовыми и общими процессами управления, позволяют определить процессы управления организацией в целом. Диагностика специальных функций управления является основой для определения уровней управляемости всей системой управления организацией.

В системах управления устойчивым развитием организации, в зависимости от параметров измерения и их характеристик, рассматриваются субъективные и объективные методы измерения. Методы сбора объективной информации предполагают выбор конкретного метода из совокупности потенциально возможных методов рассматриваемого параметра управляемости или группы параметров, измеряют одним или несколькими объективными методами сбора информации. В отдельную группу на подготовительном этапе выносятся методы работы с экспертной группой (метод экспертных оценок).

Для измерения уровней управляемости организацией используют метод экспертных оценок, а также для определения уровней управляемости всех процессов управления функционирующими в организации.

Анализ развития процессов управления по уровням управляемости показывает, какие варианты развития процессов управления могут ожидать данное предприятие в случае построения характеристики стагнации предприятия, то можно найти точку невозврата организации в систему устойчивого развития.

Акционеры и руководство организацией должны решать вопросы, связанные с управлением «человеческими ресурсами» и принимать своевременные решения по совершенствованию процессов и процедур в системах управления устойчивым социально-экономическим развитием организацией (СУУСЭРО).

В этих условиях речь идет о характеристиках коллектива предприятия, его социально-психологических характеристиках, сложившихся взаимоотношениях в профессиональных коллективах организаций, в условиях формирования и развития процессов и процедур управления человеческими ресурсами организации. Владельцы процессов управления должны включить в систему анализа эффективности работы своего процесса, характеристики, формирующие деловые качества специалистов, работников и коллектива.

Для измерения уровней управляемости специальных функций управления можно использовать метод экспертных оценок, как наиболее точный в этих условиях измерения, и разработав процедуры диагностики, подготовив экспертную группу, организовав процедуры измерения экспертных оценок заполнить Таблицу 1. Обработка экспертных анкет определения $У У\left(C Ф У_{i}\right)$ организацией.

Анализ и оценка экономической эффрективности специальной функции «Управление человеческими ресурсами (СФУЧР) определяется показателями процессов управления, определяющими долю выручки, приходящуюся на СФУЧР в общем объеме выручки. Среднегодовая выручка Предприятия $\mathrm{ABC}$, соответствующая человеческим ресурсам в годовом объеме выручки, равна 38163426 рублей. СФУЧР реализуется в текущем управлении через основные функции управления (ОФУ) и рассматриваются с помощью ОФУ, реализующихся в текущих интервалах - месяц. В каждом текущем интервале месяц будет использоваться среднемесячная выручка:

$$
W_{\text {мес }}=W_{\text {год }} / 12=38163426 / 12=3180285,5 \text { рублей. }
$$

Таблица 1 - Обработка экспертных анкет определения $У У\left(C Ф У_{i}\right)$ организацией ABC

\begin{tabular}{|c|c|c|c|c|c|c|c|c|c|c|c|c|}
\hline \multirow{2}{*}{$\begin{array}{l}\text { № } \\
\Pi / \Pi\end{array}$} & \multirow[b]{2}{*}{ СФУ } & \multicolumn{10}{|c|}{ Оценка в баллах } & \multirow{2}{*}{$\begin{array}{c}\mathrm{yY}, \\
\%\end{array}$} \\
\hline & & 1 & 2 & 3 & 4 & 5 & 6 & 7 & 8 & 9 & 10 & \\
\hline 1 & Политика & & & & ++ & + & + & + & & & & 52 \\
\hline 2 & Маркетинг & & & & + & + & + & + & + & & & 60 \\
\hline 3 & Реализация & & & & & ++ & ++ & + & & & & 58 \\
\hline 4 & Закупки & & & & & & & & ++++ & + & & 82 \\
\hline 5 & Финансы & & & & + & + & + & + & + & & & 60 \\
\hline 6 & CMK & & & & & + & + & + & ++ & & & 68 \\
\hline 7 & УЧР & & & + & +++ & + & & & & & & 40 \\
\hline 8 & Производство & & & & & & + & ++ & ++ & & & 72 \\
\hline \multicolumn{12}{|c|}{$y Y=\left(\Sigma Y y_{i}\right) / 8=492 / 8=61,5$} & 61,5 \\
\hline
\end{tabular}

Процессы управления человеческими ресурсами определяются общими функциями управления (ОФУ) учитывающими:

- $\quad$ процесс управления принятия решений;

- процесс управления контролем; 
- процесс управления учетом;

- процесс управления анализом и оценкой;

- процесс управления планированием;

- процесс управления корректировкой;

- процесс управления стимулированием.

Все семь ОФУ определяют процесс управления специальной функцией «Управление человеческими ресурсами».

Для определения эффективности управления ОФУ надо измерить их уровни управляемости (УУ), используя один из методов измерения процессов управления. Более точным и достоверным методом измерения процессов управления является метод экспертных оценок, который достаточно распространён и широко используется в подобных ситуациях в авиации. Для проведения измерения назначается экспертная группа и проводится анкетирование эффективности управления СФУЧР с помощью ОФУ. На основе данных, полученных в результате анкетирования, мы получаем оценки УУ каждой ОФУ. В таблице 2 приведены результаты анкетирования экспертами оценок по определению уровней управляемости устойчивым развитием процесса «Управление человеческими ресурсами».

Таблица 2 - Обработка экспертных оценок и определения уровней управляемости устойчивым развитием процесса «Управление человеческими ресурсами»

\begin{tabular}{|c|c|c|c|c|c|c|c|c|c|c|c|c|}
\hline \multirow{2}{*}{$\begin{array}{l}\text { № } \\
\text { П/П }\end{array}$} & \multirow{2}{*}{$\begin{array}{c}\text { Общие функции } \\
\text { управления }\end{array}$} & \multicolumn{10}{|c|}{ Оценка в баллах } & \multirow{2}{*}{$\begin{array}{c}y Y, \\
\%\end{array}$} \\
\hline & & 1 & 2 & 3 & 4 & 5 & 6 & 7 & 8 & 9 & 10 & \\
\hline 1 & 2 & 3 & 4 & 5 & 6 & 7 & 8 & 9 & 10 & 11 & 12 & \\
\hline 1 & & & & & & & & +++ & +++ & & & \\
\hline 2 & Контрол & & & & & 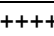 & ++ & & & & & \\
\hline 3 & Учет & & & & & + & + & ++ & ++ & & & \\
\hline 4 & Анализ и оц & & & & & +++ & ++ & + & & & & \\
\hline 5 & Планиров́ & & & & + & +++ & + & + & & & & \\
\hline 6 & Корректиро & & & & & +++ & & +++ & & & & \\
\hline 7 & Стимулирование & & & + & ++ & + & + & + & & & & \\
\hline & 505 & & & & & & & & & & & \\
\hline
\end{tabular}

Уровень управляемости СФУЧР равен 40 \% (Таблица 1), что свидетельствует о достаточно низком уровне управления. Функция УЧР вошла в низкую зону управляемости процессом управления в «Зону санации». Это указывает на нерациональное управление «Человеческими ресурсами» со стороны высшего звена управления (ВЗУ). Рассматривая процесс управления «Человеческими ресурсами» в текущем режиме таблица 2 показывает, что ОФУЧР на предприятии развиты на 59,3 \%, т. е. УУЧР равны 59,3 \%. Ответственный за процессы управления ОФУ начальник подразделения «Кадры» держит УУ в зоне санации. Для того чтобы восстановить равновесие процессов управления человеческими ресурсами, необходимо проанализировать процессы управления ОФУЧР и определить специалистов с учетом их УУОФУ.

Анализ УУОФУ по результатам экспертного опроса показывает, что самыми слабыми звеньями управления человеческими ресурсами является: планирование, стимулирование, контроль, анализ и оценка.

По полученным данным для определения зон управляемости всех ОФУЧР надо построить график уровней управляемости ОФУ $Ч Р$ (рис. 1). Анализ процессов управления определил:

○ процесс управления принятием решений равен $75 \%$, расположен в зоне стабилизации;

○ процесс управления контролем равен 53,3 \%, что соответствует зоне санации;

○ процесс управления учетом равен 68,3 \% и размещен в зоне стабилизации;

○ процесс управления анализом и оценкой равен 56,7 \%, располагается в зоне санации;

○ процесс управления планированием равен 53,3 \% и относится к зоне санации;

○ процесс управления корректировкой равен $60 \%$, распложён в зоне стабилизации;

○ процесс управления стимулированием равен $48,3 \%$ - зона санации.
Разброс уровней управляемости ОФУ (ПУ стимулированием) до 75 \% (ПУ принятием решения), это говорит о том, что часть функций управления находится в достаточно низкой зоне управляемости. Обобщающий уровень управляемости ОФУ равен 59,3\%, что соответствует зоне санации. Также в зоне санации находятся еще четыре процесса управления: контроль, анализ и оценка, планирование и стимулирование. Следовательно, специалисты, отвечающие за реализацию этих процессов, должны пройти «повышение квалификации» и в следующих интервалах времени улучшить работу своих функций (процессов) управления и выйти в зону естественных отклонений.

В случае, если они не справятся со своей задачей, таких специалистов необходимо заменить, поскольку им не по силе данная работа. В первую очередь необходимо приять меры в отношении самых слабых уровней управляемости ОФУ $Ч Р$ (контроль, анализ и оценка, планирование и стимулирование) и направить все усилия на решение данных проблем.

Определив «проблемы» в процессах ОФУ для перехода процессов управления в зону естественных отклонений или в зону устойчивого развития процессов управления надо определить время $(\Delta t)$ стабилизации процессов управления. Учитывая, что обобщенный уровень управляемости ОФУЧР равен 59,3 \%, мы принимает за стартовую точку движения всех ОФУЧР из точки to, где $У У\left(t_{0}\right)=59,3 \%$ в точку стабилизации, где УУ(ОФУЧР

Время стабилизации процессов управления определяется исходя из значений $t$ минимального, угол наклона которого равен $45^{\circ}\left(t_{\min }\right)$ и времени $t$ максимального, угол наклона которого равен около $22-27^{\circ}$. Учитывая минимальное и максимальное время стабилизации, определяют:

$$
t_{\text {среднее }}=\left(t_{\min }+t_{\text {max }}\right) / 2
$$

и принимают его за расчетное время стабилизации ( $\left.t_{c m a б}\right)$ процессов управления (рис. 2).

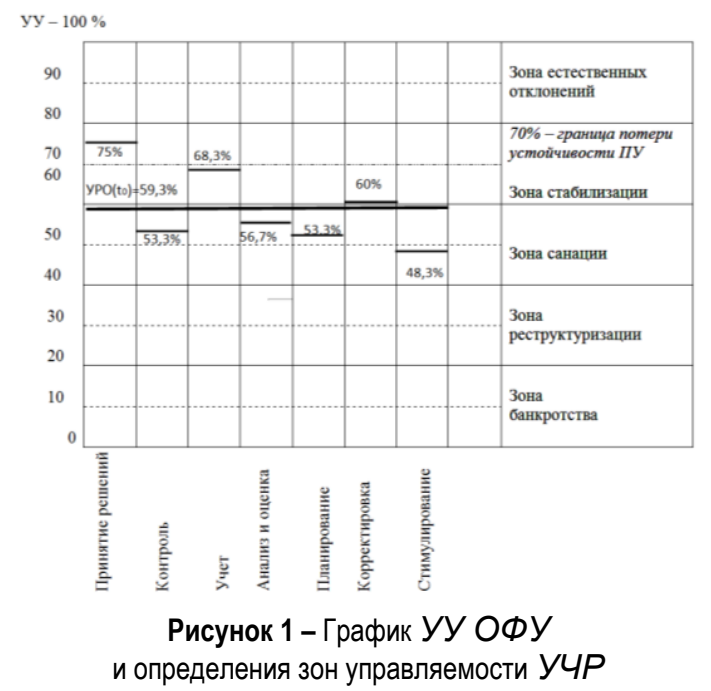

Определение времени стабилизации процессов управления ОФУЧР необходимо, чтобы найти направление, скорость и траекторию развития (TP) процессов управления. Если, разделить время стабилизации на $n$ равных отрезков времени, то мы получим равнозначные приращения уровней управляемости $\Delta У У_{i}$, стремящиеся в зону устойчивого развития организации. На каждом этапе движения $\triangle \mathrm{YY}_{i}$ появляются приращения векторов сил развития $\triangle B C P_{i}$, заставляющие двигаться $\triangle У Y_{i}$ в заданном направлении и с заданной скоростью. На рисунке 3 представлен график ТР - ОФУЧР траектории развития общих функций управления, определяющий $\triangle B C Р$ в интервалах времени $t_{1}, t_{2}, t_{3}$, при УУ ОФУЧР равен $59,3 \%$ при $t$.

На рисунке 3 показаны приращения времени $\Delta t_{i}$ и приращения УУ ОФУ в каждом интервале $\Delta t_{i}$ на 13,3 \% УУ. При шаге квантования во времени, равном $\Delta t$, происходит приращение уровне управляемости $\triangle У Y=13,3 \%$. 
Вестник Брестского государственного технического университета. 2021

Для организации движения всех процессов управления ОФУЧР необходимо построить ТР всех ОФУ ${ }_{i}$ начинающих движение в точке ( $t 0)$ и одновременно завершающие процессы управления

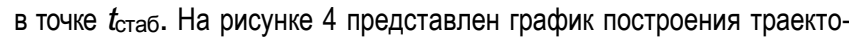
рий развития ОФУ

Все ОФУЧР начинают из достигнутых $У У_{i}$ на момент старта, т. е. в точке $t_{0}$ и каждая функция со своей скоростью движется в точку $t$ стабилизации, в которой они все $\left(О Ф У_{i}\right)$ завершают свое движение, т. е. достигают УУ равных $100 \%$, что равняется устойчивому развитию организации.

yу $-100 \%$

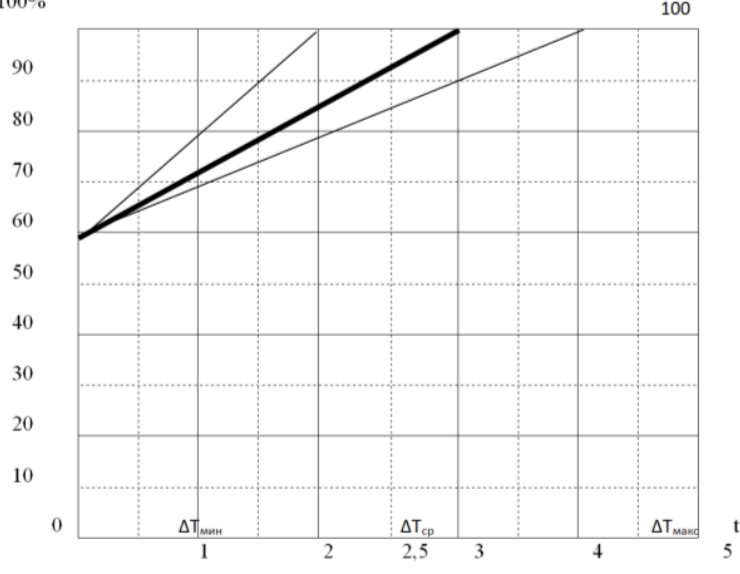

Рисунок 2 - График определения минимального, среднего и максимального интервала времени стабилизации ОФУ

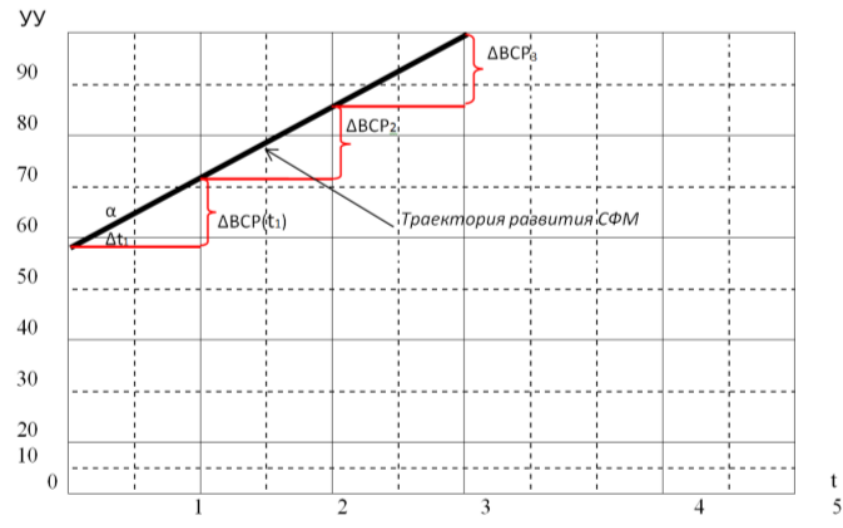

Рисунок 3 - График ТР - ОФУЧР траектории развития ОФ управления ЧР, определяющей $\triangle \mathrm{BCP}$ - приращения векторов сил развития в интервалах $t_{1}, t_{2}, t_{3} ; \mathrm{YY}\left(t_{0}\right)=59,3$ $\mathrm{y}_{\mathrm{p}, \%}$

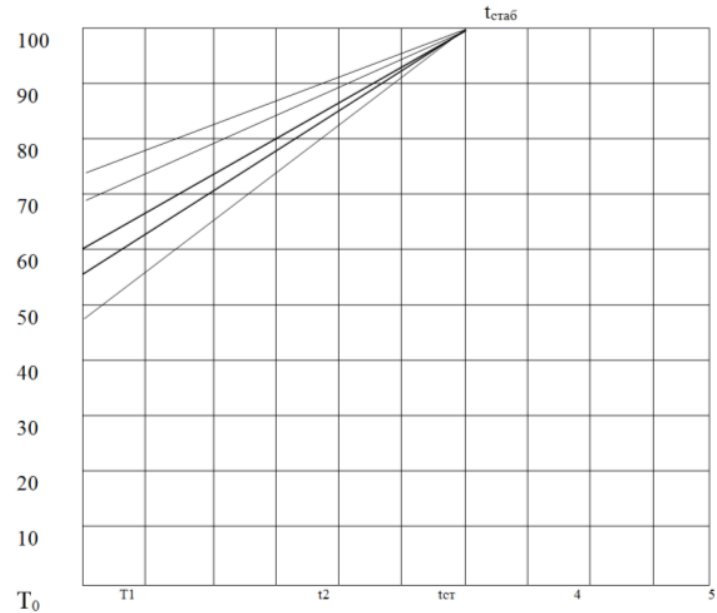

Рисунок 4 - График траекторий развитей (TP) ОФУ
Если разделить время стабилизации на четыре равных отрезка времени, то мы сможем определить приращения векторов сил развития в каждом интервале для всех ОФУЧР. Построение траектории развития ОФУ $Ч Р$ позволяет для каждого интервала времени $\Delta t$ определить $\triangle B C P_{i}$ и сформировать таблицу 3 поинтервального определения векторов сил развития в зону устойчивого развития СФУЧР.

Удерживать процесс движения на траектории развития позволяют такие процессы управления как корректировка и стимулирование.

Совокупность движения всех траекторий развития ОФУ ректирована в приращениях векторов развития и представлена в таблице 3.

Таблица 3 - Поинтервальное определение векторов сил развития в зону устойчивого развития ОФУЧР

\begin{tabular}{|c|c|c|c|c|c|c|c|c|c|c|}
\hline № & Наименование & Показатель & $1 э$ & тап & 2 эт & & $3 э$ & тап & 4 эт & \\
\hline$\pi / \Pi$ & показателей & $y_{t_{0}}$ & $\Delta \mathrm{y} y$ & $\mathrm{yy}_{\mathrm{i}}$ & $\Delta \mathrm{y} y$ & yy & $\Delta \mathrm{yy}$ & yy & $\Delta \mathrm{yy}$ & yy \\
\hline 1 & 2 & 3 & 4 & 5 & 6 & 7 & 8 & 9 & 10 & 11 \\
\hline 1 & $\begin{array}{l}\text { Принятие } \\
\text { решений }\end{array}$ & 75 & 6,25 & 81,25 & 6,25 & 87,5 & 6,25 & 93,75 & 6,25 & 100 \\
\hline 2 & Контроль & 53,3 & 11,675 & 64,975 & 11,675 & 76,65 & 11,675 & 88,325 & 11,675 & 100 \\
\hline 3 & Учет & 68,3 & 7,925 & 76,225 & 7,925 & 84,15 & 7,925 & 92,075 & 7,925 & 100 \\
\hline 4 & $\begin{array}{c}\text { Анализ } \\
\text { и оценка } \\
\end{array}$ & 56,7 & 10,825 & 67,525 & 10,825 & 78,35 & 10,825 & 89,175 & 10,825 & 100 \\
\hline 5 & Планирование & 53,3 & 11,675 & 64,975 & 11,675 & 76,65 & 11,675 & 88,325 & 11,675 & 100 \\
\hline 6 & Корректировка & 60 & 10 & 70 & 10 & 80 & 10 & 90 & 10 & 100 \\
\hline 7 & Стимулирование & 48,3 & 12,925 & 61,225 & 12,925 & 74,15 & 12,925 & 87,075 & 12,925 & 100 \\
\hline
\end{tabular}

На основании Таблицы 3 поинтервального движения векторов сил развития разрабатывается «Программа процедур соответствующих векторов сил развития, позволяющих в заданных интервалах времени достичь устойчивого развития процессов ОФУЧР» (таблица 4).

Таблица 4 - Программа процедур соответствующих векторов сил развития, позволяющих в заданных интервалах времени достичь устойчивого развития процессов ОФУЧР

\begin{tabular}{|c|c|c|c|c|c|c|}
\hline $\begin{array}{c}\text { Наименование } \\
\text { мероприятий по повы- } \\
\text { шению эффрективности } \\
\text { процессов управления } \\
\text { действиями по дости- } \\
\text { жению заданных } \Delta У y_{i} \\
\text { за } \Delta t_{i} О Ф y_{i} \\
\end{array}$ & $\begin{array}{c}\text { УУ } \\
\text { (начал } \\
\text { ьные) }\end{array}$ & $\begin{array}{l}\Delta У y \\
\text { прира- } \\
\text { щение } \\
\text { уy }\end{array}$ & 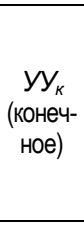 & $\begin{array}{c}\text { Долж- } \\
\text { ность } \\
\text { исполни- } \\
\text { теля, } \\
\text { ФИО }\end{array}$ & $\begin{array}{c}\text { Стоимость } \\
\text { затрат на } \\
\text { достиже- } \\
\text { ние } \Delta У Y, \\
\text { руб. }\end{array}$ & $\begin{array}{c}\text { При- } \\
\text { ме- } \\
\text { чание }\end{array}$ \\
\hline 1 & 2 & 3 & 4 & 5 & 6 & 7 \\
\hline $\begin{array}{l}\text { 1. Процесс принятия } \\
\text { решений } \\
1.1 \\
1.2\end{array}$ & & & & \begin{tabular}{|c|} 
Зам. \\
директо- \\
ра Ива- \\
нов И. И.
\end{tabular} & & \\
\hline
\end{tabular}

Оценка экономической эффективности процессов управления

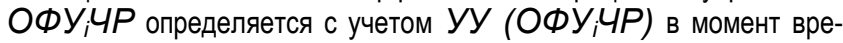
мени $t_{0}$ и удельной величины выручки, приходящейся на $1 \%$ УУ(СФУЧР). Расчеты по распределению выручки между СФУ организации выполнены в таблице 5. Определение выручки при развитии $У У\left(С Ф У_{i}\right)$ в точке $t_{0}$ определили, что специальная функция управления человеческими ресурсами потребовала выручки на сумму 38163426 рублей/год. Учитывая, что общие функции управления рассматриваются в режимах текущего управления, то для определения выручки, приходящейся на ОФУ $Ч Р$, надо рассчитывать исходя из среднемесячной выручки СФУЧР, т. е.

$$
\begin{gathered}
W\left(\text { СФУЧ } P_{\text {мес }}\right)=W(\text { СФУЧР } \\
=38163426 / 12=3180285,5
\end{gathered}
$$

Таблица 5 - Определение выручки при развитии УУ(СФУЧР)

\begin{tabular}{|c|c|c|c|}
\hline \multicolumn{4}{|c|}{ ( } \\
\hline № ח/п & $\mathrm{CФY}_{\mathrm{i}}$ & $\mathrm{YBC} \times \mathrm{VY}\left(\mathrm{C} Ф \mathrm{Y}_{\mathrm{i}}\right)=\mathrm{W}_{\mathrm{i}}$ & $\mathrm{W}\left(\mathrm{C} Ф \mathrm{Y}_{\mathrm{i} ;} ; \mathrm{t}_{0}\right)$ \\
\hline 1 & Принятие решений & $7665,19 \times 75$ & 574889,25 \\
\hline 2 & Контроль & $7665,19 \times 53,3$ & 408554,63 \\
\hline 3 & Учет & $7665,19 \times 68,3$ & 523532,48 \\
\hline 4 & Анализ и оценка & $7665,19 \times 56,7$ & 434616,27 \\
\hline 5 & Планирование & $7665,19 \times 53,3$ & 408554,63 \\
\hline 6 & Корректировка & $7665,19 \times 60$ & 459911,4 \\
\hline 7 & Стимулирование & $7665,19 \times 48,3$ & 370228,68 \\
\hline \multicolumn{3}{|c|}{ Итоговые показатели в целом по ОФУЧР } & 3180287,34 \\
\hline
\end{tabular}
в точке $t_{0}$ 
Для определения выручки, приходящейся на ОФУ $Ч Р$ в СФУЧР, надо определить среднемесячную выручку СФУЧР и распределить ее на сумму процентов УУ (ОФУ ЧР). Учитывая результаты измерения процессов управления ОФУ $\Sigma$ УУ (ОФУ ной величины стоимости $1 \%$ ОФ,УЧР определяем УВС (ОФУ

$$
\begin{gathered}
W_{\text {мес }}(\text { СФУ } Ч Р) / \Sigma \text { УУ }\left(О Ф У_{i} Ч Р\right)= \\
=3180285,5 / 414,9==7665,19 \text { рублей }
\end{gathered}
$$

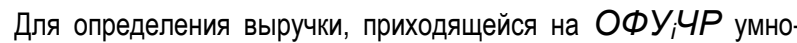
жим УУ ОФУ ЧР на УВС (ОФУЧР). Определение выручки при развитии УУ (ОФУЧР ${ }_{i}$ в в точке to приводится в таблице 6.

Определение экономической эффрективности ОФУ $Ч Р$ рассчитана в таблице 6.

Таблица 6 - Определение $W\left(О Ф У У Ч P_{i}\right)$ от развития до уровня

\begin{tabular}{|c|c|c|c|c|c|c|c|}
\hline \begin{tabular}{|l} 
№ \\
ח/
\end{tabular} & ОФУ & $\begin{array}{c}\begin{array}{c}y y \\
C \Phi y \\
\left(t_{0}\right), \%\end{array}\end{array}$ & $\begin{array}{c}\text { Выручка при } \\
\text { формирова- } \\
\text { нии } \\
\text { уУ(СФУ } \\
\text { при to, руб. }\end{array}$ & $\begin{array}{l}\text { уу \% } \\
\text { СФУi } \\
\text { при } \\
\text { yPO, \% }\end{array}$ & $\begin{array}{c}\Delta \mathrm{y} \\
\text { при } \\
\text { yPO, } \\
\%\end{array}$ & $\begin{array}{c}\Delta W\left(C \Phi Y_{i}\right) \\
\text { при УРО, } \\
\text { руб. }\end{array}$ & $\begin{array}{c}\Sigma W(C \Phi У \\
)=W\left(t_{0}\right) \\
+ \\
\Delta W(\mathrm{YPO})\end{array}$ \\
\hline \begin{tabular}{|l|}
1 \\
\end{tabular} & 2 & 3 & 4 & 5 & 6 & 7 & 8 \\
\hline 1 & $\begin{array}{l}\text { Принятие } \\
\text { решения }\end{array}$ & 75 & 574889,25 & 100 & 25 & 191629,75 & 766519 \\
\hline \begin{tabular}{|l|}
2 \\
\end{tabular} & & 3,3 & 63 & $\overline{10}$ & \begin{tabular}{|l|}
46,7 \\
\end{tabular} & 357 & 766519 \\
\hline 3 & VYeT & 68,3 & 523532,48 & 100 & 31,7 & & 766519 \\
\hline 4 & $\begin{array}{c}\text { Анализ } \\
\text { и оценка } \\
\end{array}$ & 56,7 & 434616,27 & 100 & 43,3 & 331902,73 & 766519 \\
\hline 5 & $\begin{array}{c}\begin{array}{c}\text { Планирова- } \\
\text { ние }\end{array} \\
\end{array}$ & 53,3 & 8554,63 & 100 & 46,7 & 4,37 & 6519 \\
\hline 6 & $\begin{array}{l}\text { Корректи- } \\
\text { ровка }\end{array}$ & 60 & 9911,4 & 100 & 40 & 06607,6 & 6519 \\
\hline \multirow[t]{2}{*}{7} & $\begin{array}{c}\text { Стимулиро- } \\
\text { вание }\end{array}$ & 48,3 & 228,68 & 100 & 51,7 & 396290,32 & 766519 \\
\hline & yyPO & $414,9 \%$ & 3180287,34 & 700 & 285,1 & 2185345,66 & 5365633 \\
\hline
\end{tabular}
устойчивого развития

\section{Заключение}

Исходя из проведенного анализа видно, что функция управления человеческими ресурсами находится в зоне санации. В этой зоне консалтингу уже сложно получить высокие результаты, поскольку это зона «банковских решений», то есть, когда банк, презентующий данную организацию, понимает, что акционеры предприятия уже не смогут вернуть банку свои долги, и банк может (или должен) за долги забрать у владельцев все оборудование и перевести предприятие в систему «антикризисного управления». В этих условиях банк заключает договор $\mathrm{C}$ «Менеджерами по антикризисному управлению и санации» (МАУСами) на вывод предприятия в зону устойчивого развития (УУ процессов управления находятся в диапазоне от $95 \%$ УУ до $85 \%$ УУ). Хочется также отметить, что это менеджеры, которые используют инновационные технологии эффективного менеджмента (ИТЭМ). В соответствии с расчетами по определению экономической эффективности УЧР следует отметить, что для достижения поставленной цели необходимо 5365633 рублей, а также постоянный контроль и мониторинг за выполнением действий по достижению устойчивых показателей развития.

Алгоритм решения комплексной задачи по измерению уровней управляемости человеческими ресурсами затрагивает сложные функции управления, подразделяемые на специальные и общие. Специальные функции управления нужны высшему звену управления организацией, и они с их помощью создают условия устойчивого развития организации. Помимо этого, особенность решения поставленного вопроса заключается в том, что, опираясь на общие функции управления, также рассматривается условия второй системь управления организацией, это начальники подразделения и специалисты, которые оперируют общими функциями управления и создают позитивную систему реализации управленческих воздействий, исходящих от высшего звена управления.

\section{Список цитированных источников}

1. Комплекс мер на 2016-2020 годы по стимулированию внедрения в экономику страны передовых методик и современных международных систем управления качеством [Электронный ресурс] // Слуцкий районный исполнительный комитет. - Режим доступа: http: I/ www.slutsk.minsk-region.by/dfiles/000965_12543_2603201814.pdf. - Дата доступа: 23.03.2021.

2. «Система мер по управлению качеством в промышленном комплексе Брестской области на 2017-2020 годы».

3. Менеджмент качества. Методические материалы по стандартам ISO серии 9000 версии 2008 года / под общей редакцией Гуревича В. Л. - Минск : БелГИСС, 2009. - 152 с.

4. Высоцкий, О.А. Теория измерения управляемости хозяйственной деятельностью предприятий / О. А. Высоцкий; под науч. ред. Р. С. Седегова. - Мн.: ИООО «Право и экономика», 2004. - 396 с.

5. Высоцкий, О. А. Основы устойчивого развития производственной организации / О. А. Высоцкий, И.М.Гарчук, Н.С.Данилова; под научн. ред. В. Ф. Медведева; Брестский государственный технический университет. - Минск : ИООО «Право и экономика», 2015. 358 с. - (Серия «Высшая школа бизнеса»).

6. Менеджмент для достижения устойчивого успеха организации. Подход на основе менеджмента качества. - Минск - Госстандарт, 2010.

7. Высоцкий, О. А. Основы инженерной психологии / О. А. Высоцкий. Брест, Брестский политехнический институт, Центр «Персонал», 1995. $-260 \mathrm{C}$

8. Высоцкий, О. А. Методология измерения и практикум по управлению организацией (в стартовых условиях устойчивого развития организации) / О. А. Высоцкий, И. М. Гарчук, Н. С. Данилова; Е. В. Зацепина, Н. Г. Кот; под научн. ред. О. А. Высоцкого. - Минск : «Право и экономика», 2016. - 272 с. - (Серия «Высшая школа бизнеса»).

9. Беляцкий Н. П. Управление персоналом: учеб. пособие / Беляцкий Н. П., Велесько С. Е., Ройш П. - Минск: Интерпрессервис, Экоперспектива, 2002. - 352 с.

10. Менеджмент организации. Руководящие указания по достижению экономического эффректа в системе менеджмента качества: ГОСТ Р ИСЩ 10014-2008. - Введ. 01.12.2009. - Москва : ФГУП «СТАНДАРТИНФОРМ», 2009. - 27 c.

\section{References}

1. Kompleks mer na 2016-2020 gody po stimulirovaniyu vnedreniya v ekonomiku strany peredovyh metodik i sovremennyh mezhdunarodnyh sistem upravleniya kachestvom [Elektronnyj resurs] // Sluckij rajonny] ispolnitel'nyj komitet. - Rezhim dostupa: http: // www.slutsk.minskregion.by/dfiles/000965_12543_-2603201814.pdf. - Data dostupa: 23.03.2021.

2. «Sistema mer po upravleniyu kachestvom v promyshlennom komplekse Brestskoj oblasti na 2017-2020 gody».

3. Menedzhment kachestva. Metodicheskie materialy po standartam ISO serii 9000 versii 2008 goda / pod obshchej redakciej Gurevicha V. L. Minsk : BelGISS, 2009. - $152 \mathrm{~s}$.

4. Vysockij, O. A. Teoriya izmereniya upravlyaemosti hozyajstvennoj deyatel'nost'yu predpriyatij / O. A. Vysockij; pod nauch. red. R. S. Sedegova. - Mn.: IOOO «Pravo i ekonomika», 2004. - $396 \mathrm{~s}$.

5. Vysockij, O. A. Osnovy ustojchivogo razvitiya proizvodstvennoj organizacii / O. A. Vysockii, I. M. Garchuk, N. S. Danilova; pod nauchn. red. V. F. Medvedeva; Brestskij gosudarstvennyj tekhnicheskij universitet. - Minsk : IOOO «Pravo i ekonomika», 2015. - 358 s. - (Seriya «Vysshaya shkola biznesa»).

6. Menedzhment dlya dostizheniya ustojchivogo uspekha organizacii. Podhod na osnove menedzhmenta kachestva. - Minsk - Gosstandart, 2010.

7. Vysockij, O. A. Osnovy inzhenernoj psihologii / O. A. Vysockij. - Brest, Brestskij politekhnicheskij institut, Centr «Personal», 1995. - $260 \mathrm{~s}$.

8. Vysockii, O. A. Metodologiya izmereniya i praktikum po upravleniyu organizaciej (v startovyh usloviyah ustojchivogo razvitiya organizacii) / O. A. Vysockij, I. M. Garchuk, N. S. Danilova; E. V. Zacepina, N. G. Kot; pod nauchn. red. O. A. Vysockogo. - Minsk: «Pravo i ekonomika», 2016. - 272 s. - (Seriya «Vysshaya shkola biznesa»).

9. Belyackij N. P. Upravlenie personalom: ucheb. posobie / Belyackij N. P., Veles'ko S. E., Rojsh P. - Minsk: Interpresservis, Ekoperspektiva, 2002. $-352 \mathrm{~s}$.

10. Menedzhment organizacii. Rukovodyashchie ukazaniya po dostizheniyu ekonomicheskogo effekta $v$ sisteme menedzhmenta kachestva: GOST R ISSHCH 10014-2008. - Vved. 01.12.2009. - Moskva : FGUP «STANDARTINFORM», 2009. - $27 \mathrm{~s}$.

Материал поступил в редакцию 05.05.2021 